\title{
Eating Defensively: The Nutrition and Food Safety Benefits of Cooked Produce ${ }^{1}$
}

\author{
Morgan Dehnard, Amy Simonne, and Gail P. A. Kauwell²
}

\section{Introduction}

Vegetables are an important part of our diet. In fact, the U.S. Dietary Guidelines recommends that fruits and vegetables fill half our plate (USDA, 2010). The health benefits of vegetables stem from the fact they are packed with vitamins, minerals, and fiber, yet low in calories. Current nutrition trends such as the "raw food diet" may lead consumers to believe that raw leafy vegetables are more nutritious than cooked vegetables, despite research showing that cooked vegetables make important nutritional contributions. This publication describes the nutrient retention and quality of cooked vegetables, explains why cooking vegetables is appropriate for consumers with food safety concerns, and provides tips for preparing cooked vegetables.

\section{Cooked Vegetables Are Nutrient Rich}

Many people believe that raw vegetables are nutritionally superior to cooked forms (Rickman, Barrett, \& Bruhn, 2007). The idea that "raw is best" has formed the basis for popular fads such as "juicing," "cleanses," and the "raw food diet"; however, not many research studies support this idea. In contrast, many research studies support the contribution of cooked vegetables to the American diet.

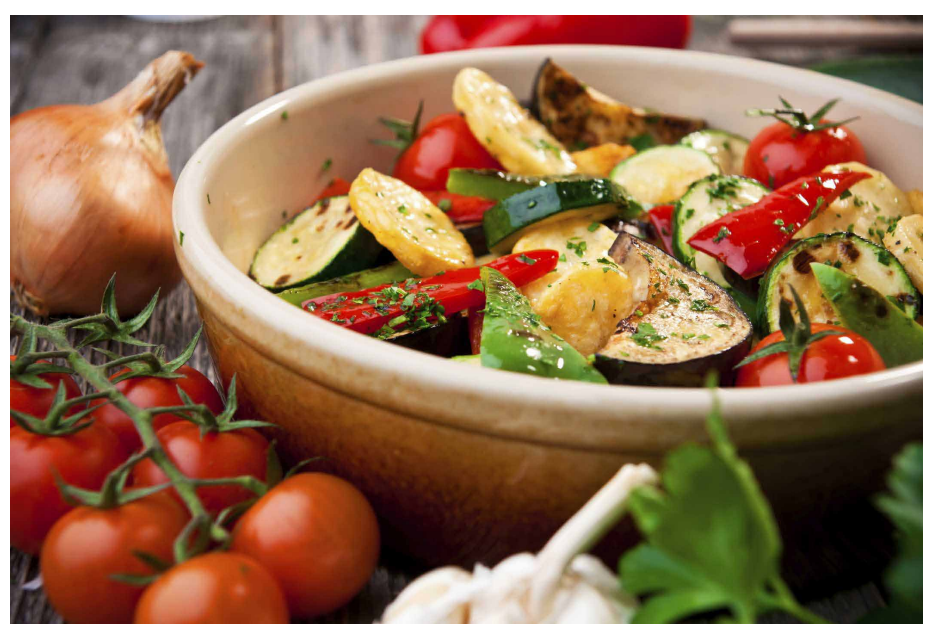

Figure 1. Cooked vegetables are nutrient rich and can make some nutrients easier to digest and absorb.

Credits: iStock

Will cooked greens and other vegetables still provide the vitamins and minerals available in their raw form? The answer to this question may surprise you. Some nutrients, such as vitamin $\mathrm{C}$ and folate, are water soluble, meaning that they dissolve in water (Rickman, Bruhn, \& Barrett, 2007). Using water and applying heat to prepare foods that contain water-soluble vitamins can reduce the amounts of these nutrients present in food (Rickman, Bruhn, \& Barrett, 2007). However, because vegetables such as spinach cook down and reduce in volume, a cup of cooked spinach actually represents a lot more spinach than a cup of raw spinach

1. This document is FCS80029, one of a series of the Department of Family, Youth and Community Sciences, UF/IFAS Extension. Original publication date: October 2013. Visit the EDIS website at http://edis.ifas.ufl.edu.

2. Morgan Dehnard, dietetic intern, Master of Science-Dietetic Internship Program, Food Science and Human Nutrition Department; Amy Simonne, professor, Department of Family, Youth and Community Sciences; and Gail P. A. Kauwell, professor, Food Science and Human Nutrition Department; UF/IFAS Extension, Gainesville, FL 32611. 
(National Agricultural Library, 2011). The difference in the amount of spinach in one cup of cooked product can make up for the loss of water-soluble vitamins that occurs during cooking (National Agricultural Library, 2011).

While some nutrients are lost as a result of the heating process, others actually become more bioavailable after the food has been heated. This means that the nutrients are more easily absorbed by the body (Van het Hof, West, Weststrate, \& Hautvast, 2000; Bugianesi et al., 2004). When vegetables are cooked or processed, they become softer, making certain nutrients in these foods easier to digest and absorb (Rickman, Bruhn, \& Barrett, 2007).

As an example, consider what happens to spinach during the boiling process. As the spinach cooks, it softens and reduces in volume. There are many more leaves of spinach in a single cup of cooked spinach compared to raw spinach (National Agricultural Library, 2011). As a result, eating a cup of cooked spinach makes it easier to consume more fiber. Sensitive water-soluble nutrients like vitamin $\mathrm{C}$ and folate are leached out of the spinach and into the water. Vitamin A, iron, and calcium become more bioavailable because of the softening of the plant cells, so the amount of these nutrients that can be absorbed by the body increases (Rickman, Bruhn, \& Barrett, 2007). In fact, a study comparing the bioavailability of beta-carotene, a form of vitamin A, in raw versus cooked spinach and carrots showed that three times as much of this nutrient was absorbed when these foods were cooked compared to when they were raw (Rock et al., 1998).

Studies have shown that the amount of water-soluble nutrients lost during cooking depends on the cooking method. Preparation methods that use high heat and water, such as boiling, are the least effective in retaining watersoluble nutrients (Jiménez-Monreal, Garcia-Diz, MartinezTome, Mariscal, \& Murcia, 2009). In the example above, the spinach was prepared by boiling. This method has the most harmful effects on heat-sensitive nutrients, so the greatest losses occur when this method is used. Microwaving has been shown to increase the antioxidant activity of most vegetables, while stir-frying or sautéing retains more nutrients than boiling, but less than microwaving (Jiménez-Monreal et al., 2009). Antioxidants are substances that protect your body against free radical damage and include beta-carotene, lutein, lycopene, selenium, and vitamins $\mathrm{A}, \mathrm{C}$, and $\mathrm{E}$ (NIH, 2013).

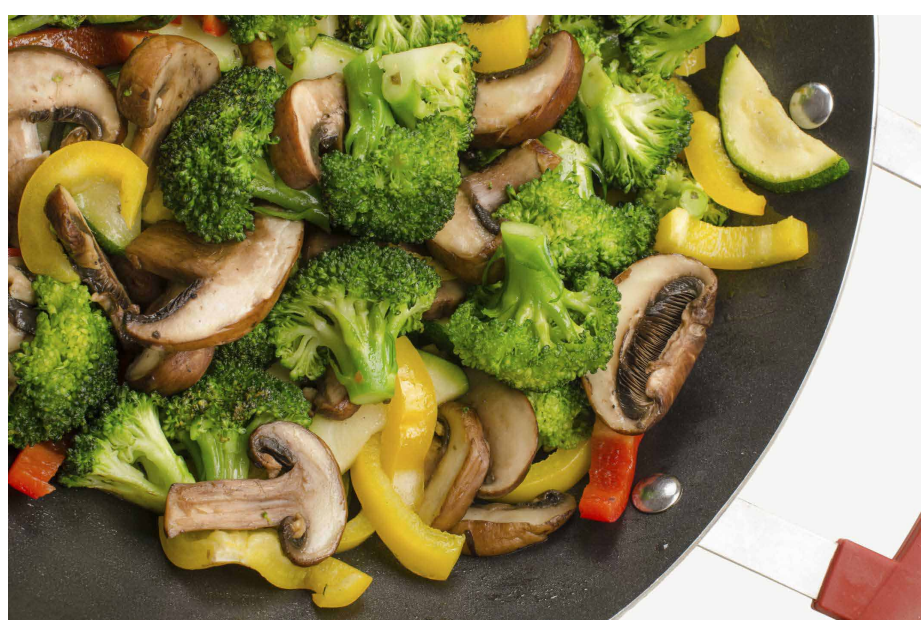

Figure 2. One easy way to prepare vegetables is to stir-fry them. Credits: iStock

\section{Cooked Vegetables Are More Food Safe}

From 1996 to 2008, there were 82 fresh produce-associated foodborne illness outbreaks (U.S. FDA, 2009). Notably, more than one-third of these outbreaks were related to leafy green produce. The CDC has noted an increase in producerelated outbreaks since the 1970s, and this has been attributed to factors such as better surveillance, increased global trade, an aging population, and increased encouragement to consume fresh produce (U.S. FDA, 2012).

Washing your produce correctly is a good food safety practice, but will not completely remove all microbes that may be present (Zander \& Bunning, 2010). For tips on washing produce, refer to the EDIS publication, Fresh Produce: Safe Handling Practices for Consumers (http://edis. ifas.ufl.edu/fy481). Cooking vegetables is the surest way to destroy pathogens in food and decrease your risk for foodborne illness.

\section{For Healthy Americans}

For most people in good health, produce-associated foodborne illness is not life threatening. Although there is risk of fresh produce being contaminated, both raw and cooked vegetables are good additions to a healthy diet. To reduce your risk of becoming ill from contaminated raw produce, take these basic food safety measures:

- Always wash your hands for about 20 seconds with hot soapy water before preparing food.

- Wash produce with cool water just before eating.

- Cut away damaged areas on produce, and remove the outer leaves on lettuce heads. 
- Never prepare produce on the same cutting boards as raw meat or poultry (Academy of Nutrition and Dietetics, 2013).

\section{For At-Risk Populations}

For immune-compromised individuals, food safety is especially important. These populations include people who have had organ transplants (e.g., heart, liver, or kidney), pregnant women, older adults, newborns, and people with cancer, HIV/AIDS, or diabetes (Food Safety and Inspection Service, 2012). Having a compromised immune system puts these individuals at higher risk for all foodborne diseases, including produce-related foodborne infections from pathogens such as Listeria, E. coli, and Salmonella. The USDA's Food Safety and Inspection Service has developed food safety recommendations for these special populations, available at http://www.fsis.usda.gov/wps/portal/fsis/topics/ food-safety-education/get-answers/food-safety-fact-sheets/ at-risk-populations.

The vitamins and minerals in vegetables are important for everyone, especially at-risk populations. If you are at risk for foodborne illness and choose to avoid raw produce, you can make up for potential cooking losses of water-soluble vitamins by consuming foods less likely to be contaminated, such as washed and peeled carrots, sweet bell peppers, and pasteurized $100 \%$ vegetable juice. When purchasing vegetable juices, the most "food-safe" thing to do is to buy them from a grocery store and to select only those products that say "pasteurized" on the label.

\section{Taking the Concepts to the Kitchen}

Whether you are preparing cooked or raw vegetables, always follow best food safety practices. To start, avoid selecting produce that appears damaged or spoiled. When you return home from the grocery store, place produce in the fridge, away from meat items. When you are ready to prepare produce, rinse it with cool water, and use different knives and cutting boards from the ones used to prepare meat and other foods.

There are many ways to cook vegetables. Use these tips to choose the best method for your situation. No matter which method you choose, always keep the following information in mind:

- Cooked vegetables taste and look their best right after being prepared.

- Cooking in small batches is the best way to ensure uniform cooking and color retention.
- Cook vegetables until they are "tender-crisp." Overcooked vegetables have fewer nutrients and a mushy taste.

Boil: Add fresh or frozen produce to boiling water. Wait for the water to start boiling again. Reduce the heat to simmer (just below boiling) and cook until the vegetables reach the desired tenderness. Drain immediately. Leave the lid off to retain bright colors!

Microwave: Place the vegetables in a covered, microwavesafe dish. Soft vegetables, like spinach, should be washed and slightly wet. Heat soft vegetables for 1-2 minutes. Harder vegetables, like carrots, should be covered in water and cooked for 6-8 minutes. Using less water and a shorter cooking time maximizes nutrient retention.

Stir-Fry/Sauté: Cut vegetables into small pieces. For stirfried vegetables, add 1-2 tablespoons of oil to the frying pan. Add hard vegetables that take longer to cook first. After a few minutes, add softer vegetables that cook quickly. Remove from heat when tender. To sauté, add only a small amount of oil.

\section{Recipe: Creamy Veggie Pasta}

A key recommendation of the Dietary Guidelines is to "eat a variety of vegetables, especially dark green and red and orange vegetables" (USDA, 2010). This recipe incorporates more color and nutrients than a typical serving of pasta. Recipe serves 4.

Ingredients:

- 1 cup sliced carrots or carrot chips

- 1 large tomato, chopped into small pieces

- 9 ounces spinach (fresh or frozen)

- 12 ounces broccoli (fresh or frozen)

- Optional: mushrooms, minced garlic, chopped onions, other vegetables

- 8 ounces thin whole-wheat spaghetti

- 2 tablespoons olive oil

- 1 cup plain yogurt

- 2 tablespoons Parmesan cheese

- Creole seasoning to taste

1. Prepare pasta according to box directions.

2. Add olive oil to large skillet and add carrots and any frozen vegetables first. 
3. After about five minutes, add the rest of the vegetables. If you are using fresh spinach, add it last. Spinach cooks very quickly and does not taste good when overcooked.

4. Add sautéed vegetables to the pot of prepared pasta. Add the yogurt and parmesan cheese and toss to mix the ingredients. For a touch of spice, add Creole seasoning. Enjoy!

\section{Summary}

Choosing to cook your vegetables is a sound decision and adds variety and nutritional quality to your diet. You can feel good about preparing cooked vegetable dishes for yourself, your friends, and your family. Extreme diets exclusively composed of raw foods or juices are less food safe and are not nutritionally superior. To meet the USDA's Dietary Guidelines for vegetables, focus on adding a variety of colorful plant sources to your diet. Experiment with new recipes and preparation methods to find vegetable-based dishes you enjoy.

\section{References}

Academy of Nutrition and Dietetics. (2013). Which foods make Americans ill? Whether chicken or salad, food safety at homeis key to avoiding illness, says Academy of Nutrition and Dietetics. Retrieved from http://www.eatright.org/ Media/content.aspx?id=6442474685

Bugianesi, R., Salucci, M., Leonardi, C., Ferracane, R., Catasta, G., Azzini, E., \& Maiani, G. (2004). Effect of domestic cooking on human bioavailability of naringenin, chlorogenic acid, lycopene and beta-carotene in cherry tomatoes. Eur J Nutr. 43(6), 360-366.

Food Safety and Inspection Service, USDA. (2012). At-risk populations. Retrieved from http://www.fsis.usda.gov/ wps/portal/fsis/topics/food-safety-education/get-answers/ food-safety-fact-sheets/at-risk-populations.

Jiménez-Monreal, A. M., García-Diz, L., Martínez-Tomé, M., Mariscal, M., and Murcia, M. A. (2009). Influence of cooking methods on antioxidant activity of vegetables. $J$ Food Sci. 74(3), 97-103.

National Agricultural Library. (2011). USDA national nutrient database. Agricultural Research Service, USDA. Retrieved from http://ndb.nal.usda.gov/

National Institutes of Health (NIH), Medline Plus. (2013). Antioxidants. Retrieved from http://www.nlm.nih.gov/ medlineplus/antioxidants.html
Rickman, J. C., Barrett, D., \& Bruhn, C. (2007). Nutritional comparison of fresh, frozen, and canned fruits and vegetables. Part 1. Vitamins C and B and phenolic compounds. J. Sci Food Agric. (in press). doi: 10.1002/jsfa.2825

Rickman, J. C., Bruhn, C., and Barrett, D. (2007). Nutritional comparison of fresh, frozen, and canned fruits and vegetables II. Vitamin A and carotenoids, vitamin E, minerals and fiber. J. Sci. Food Agric. 87, 1185-1196.

Rock, C. L., Lovalvo, J. L., Emenhiser, C., Ruffin, M. T., Flatt, S. W., \& Schwartz, S. J. (1998). Bioavailability of $\beta$-carotene is lower in raw than in processed carrots and spinach in women. J. Nutr. 128(5), 913-916.

USDA. U.S. Department of Health and Human Services. (2010). Dietary guidelines for Americans. Retrieved from http://www.health.gov/dietaryguidelines/dga2010/ DietaryGuidelines2010.pdf

U.S. FDA. (2012). Outbreaks associated with fresh and fresh-cut produce. Incidence, growth, and survival of pathogens in fresh and fresh-cut produce. In Analysis and evaluation of preventive control measures for the control and reduction/elimination of microbial hazards on fresh and fresh-cut produce (Chapter IV). Retrieved from http://www. fda.gov/Food/FoodScienceResearch/SafePracticesforFoodProcesses/ucm091265.htm

Van het Hof, K. H., West, C. E., Weststrate, J. A., \& Hautvast, J. G. (2000). Dietary factors that affect the bioavailability of carotenoids. J Nutr. 130(3), 913-916.

Zander, A., \& Bunning, M. (2010). Guide to washing fresh produce. No. 9.380. Colorado State University Extension. Retrieved from http://www.ext.colostate.edu/pubs/foodnut/09380.html. 